\title{
EXPLORAÇÃO, CONTROLE E HIERARQUIA: o trabalho feminino da produção rígida ao toyotismo'
}

\author{
Amanda Chayane de Oliveira Veiga ${ }^{2}$ \\ Fernando de Araújo Bizerra ${ }^{3}$
}

Resumo: Considerando a entrada significativa das mulheres no mercado de trabalho desde o século passado, a reflexão que se segue, filiada à perspectiva do materialismo histórico-dialético, analisa a exploração, o controle e a hierarquia que o trabalho feminino esteve submetido durante a produção rígida e, após, no contexto da toyotismo que tende a ampliar e diversificar os mecanismos de exploração da força de trabalho, afetando diretamente os processos, as relações e as condições de trabalho em cada região e país de forma específica.

Palavras-chave: Divisão sexual do trabalho; Produção capitalista; Força de trabalho feminina.

Abstract: Considering the significant entry of women into the labor market since the last century, the following reflection, affiliated with the perspective of historicaldialectical materialism, analyzes the exploitation, control, and hierarchy that feminine labor was subjected to during rigid production, and then in the context of toyotism that tends to broaden and diversify the mechanisms Exploitation of the workforce, directly affecting the processes, relationships and working conditions in each region and country in a specific way.

Keywords: Sexual division of labor; Capitalist production; Feminine work force.

\section{Introdução}

Um olhar atento sobre a realidade demonstra, sem lugar a dúvidas, que o conjunto dos trabalhadores - ou seja, todos/as aqueles/as que não possuem os meios de produção e são condicionados/as a vender sua força de trabalho em troca de um salário necessário para garantir, ainda que minimamente, sua sobrevivência - experimentam em seu cotidiano, embora com diferenças

\footnotetext{
${ }^{1}$ DOI: https://doi.org/10.22409/tn.15i27.p9635

2 Graduada em Serviço Social pela Universidade Federal de Alagoas - UFAL/Campus ArapiracaUnidade Educacional de Palmeira dos Índios. E-mail: <amandachayane92@hotmail.com>.

3 Assistente Social, Mestre pelo Programa de Pós-Graduação em Serviço Social (PPGSS) da Universidade Federal de Alagoas (UFAL). Professor Assistente do Curso de Serviço Social da UFAL - Campus Arapiraca/Unidade Educacional de Palmeira dos Índios. Membro do Grupo de Pesquisa sobre Reprodução Social (FSSO/UFAL). E-mail: <nando_epial@hotmail.com>.
}

TrabalhoNecessario - www.uff.br/trabalhonecessario; Ano 15, №27/2017 
consideráveis, os efeitos perversos do trabalho realizado sob o domínio do capital nos últimos séculos: exploração, controle e hierarquias.

Intitulado "As mulheres no mercado de trabalho: medir os progressos e identificar os desafios", o relatório emitido em 2010 pela Organização Internacional do Trabalho (OIT) evidencia que, passada mais de uma década da Quarta Conferência Mundial sobre as Mulheres ${ }^{3}$, a exploração e a precarização das atividades por elas realizadas tem se aprofundado. Não obstante a entrada em massa das mulheres nas estatísticas relacionadas ao emprego durante 0 século XX e no alvorecer do século XXI, a igualdade de condições no mercado de trabalho não é uma realidade objetiva, considerando-se, pois, a existência da divisão sexual que permeia as relações trabalhistas em todos os continentes.

Recentemente, um novo documento elaborado pelo mesmo órgão mostra que ao longo de sua vida profissional as mulheres continuam a enfrentar, quer nos países de rendimento elevado, quer naqueles de baixo rendimento, enormes obstáculos na caminhada para encontrar e manter empregos decentes. A despeito de alguns indicadores positivos documentarem a presença das mulheres no mercado de trabalho, permanecem intactas as segregações setorial e profissional que redesenham as disparidades de gênero. Não é de se estranhar que as mulheres estejam representadas nas ocupações num número limitado de setores e profissões. "Mulheres no trabalho: tendências 2016" reúne dados de 178 países pesquisados que permitem o seguinte diagnóstico: as desigualdades entre homens e mulheres persistem em um amplo espectro do mercado de trabalho global no tocante às oportunidades, ao tratamento e/ou aos resultados.

Contrapondo-se às vulgatas que afirmam que as mulheres já alçaram um patamar de igualdade social com os homens no mercado de trabalho, este artigo objetiva expor algumas expressões do trabalho feminino ${ }^{4}$ durante a vigência do

\footnotetext{
${ }^{3}$ Tal Conferência visou adotar uma plataforma ousada para uma ação global que promovesse a igualdade de gênero e a autonomia das mulheres.

${ }^{4}$ Nos marcos do modo de produção capitalista a mulher não apenas participa do processo produtivo. Além de está inserida em locais de trabalho que dizem respeito à produção, a mulher desenvolve outras atividades - na maioria dos casos não remuneradas - que são imprescindíveis para a sociedade ao se situarem no âmbito da reprodução. Quanto a isso, destaca Saffioti (1987, p. 9) que "a responsabilidade última pela casa e pelos filhos é imputada ao elemento feminino. Torna-se, pois, clara a atribuição, por parte da sociedade, do espaço doméstico a mulher. Trabalhando em troca de um salário ou não, na fábrica, no escritório, na escola, no comércio, ou a domicílio, como é caso de muitas mulheres que costuram, fazem crochê, tricô, doces e salgados, 
binômio taylorista-fordista e, seguidamente, do toyotismo. É certo que em momento algum houve pretensão de se fazer uma análise exaustiva. É certo também que nosso esforço de pesquisa não foi capaz de abarcar senão uma pequena (mas, relevante) porção da miríade de estudos que evidenciam o universo multifacetado das mulheres trabalhadoras atingidas pela divisão sexual do trabalho que controla, oprime, subalterniza, explora e as discrimina pelo seu sexo e pela classe social a qual elas pertencem.

Vale ressaltar que os estudos acerca da divisão sexual do trabalho dão mostras que ela tem sido interpretada por distintas visões. Em uma delas, considera-se que as desigualdades entre as tarefas realizadas por homens e as destinadas às mulheres remetem, em última instância, à "natureza feminina" que faz aquelas serem estereotipadas como mais dóceis, pacientes, cuidadosas e menos combativas. Não se explica por que a exploração se exerce mais fortemente sobre as mulheres e quando se tenta dar alguma explicação para a sua ausência em determinados postos de trabalho ocupados excepcionalmente por homens, justifica-se: "ela é bem menos equipada no mercado do emprego; entenda-se menos formada, mas também menos disponível objetivamente" devido os encargos familiares "e subjetivamente (por causa do investimento das mulheres no 'extratrabalho', isto é, na família)" (KERGOAT, 1989, p. 90).

De outro ângulo, e é este que orientou o processo investigativo que resulta nesse estudo, as desigualdades resultantes da divisão sexual do trabalho "não têm a ver com um mais ou menos, mas devem ser relacionadas, não a modulações, mas a diferenças, contradições entre os dois sexos, a relações sociais, em suma" (KERGOAT, 1989, p. 93, grifos da autora). A divisão (hierárquica e desigual) das atividades que competem ao homem e à mulher não ocorre, como será demonstrado na sequência, "naturalmente". Desnaturalizar essa realidade numa sociedade como a nossa é uma tarefa tão desafiadora quanto necessária.

a mulher é socialmente responsável pela manutenção da ordem na residência e pela criação e educação dos filhos. Assim, por maiores que sejam as diferenças de renda encontradas no seio do contingente feminino, permanece esta identidade básica entre todas as mulheres". Pelos limites da análise aqui presente, não tematizaremos esse aspecto. Isso, contudo, não significa que desconsideramos sua existência. Para uma discussão aprofundada sobre o trabalho feminino na esfera da reprodução, Cf. Saffioti (1987) e Nogueira (2010).

TrabalhoNecessario - www.uff.br/trabalhonecessario; Ano 15, №27/2017 


\section{O binômio taylorismo-fordismo e o trabalho feminino}

O taylorismo foi criado em finais do século XIX por Frederick Winslow Taylor, um jovem estadunidense de família rica que abandonou os estudos para trabalhar como operário em uma metalúrgica. Através dessa vivência, ele notou que a capacidade produtiva de um trabalhador de experiência média era sempre maior que a sua produção na empresa. Estava cônscio que os operários podiam produzir mais do que o já alcançado e que a troca constante de ferramentas acabava por diminuir a produtividade. Taylor, a partir dos Princípios de administração científica, consolidou esforços no sentido de aplicar os métodos da ciência às questões relacionadas ao trabalho nas empresas que se expandiam.

Taylor (2008) define que o objetivo da administração "deve ser o de assegurar o máximo de prosperidade ao patrão e, ao mesmo tempo, o máximo de prosperidade ao empregado". O aumento da produção representaria "prosperidade" para os principais sujeitos do processo: empregado e empregador. A administração científica pressupõe que ambos têm os mesmos interesses: "de que a prosperidade do empregador não pode existir se não for acompanhada da prosperidade do empregado, e vice-versa". Sendo assim, é preciso "dar ao trabalhador o que ele mais deseja - altos salários - e ao empregador também o que ele realmente almeja - baixo custo de produção" (TAYLOR, 2008, p. 24). Percebe-se que Taylor desconsidera radicalmente a existência dos antagonismos que permeiam a relação-capital. Não há como, nos marcos do sistema capitalista, capitalistas e trabalhadores comungarem do mesmo interesse. A posição ocupada por cada um desses sujeitos no processo produtivo define seus objetivos particulares e impede que haja uma coexistência pacífica entre ambos. Em profunda oposição aos trabalhadores, os capitalistas buscam, a qualquer custo, perenizar as condições que lhes garantem a exploração da força de trabalho. Por essas razões, nada mais insustentável, do ponto de vista da dinâmica concreta do capitalismo, que a afirmação de interesses comuns entre capital e trabalho.

Pensando em como evitar o desperdício de tempo nas fábricas, Taylor (2008, p. 26) defende que "o trabalho da empresa [deve ser] realizado com o 
menor gasto de esforço humano, combinado com o menor gasto das matériasprimas, com a menor inversão de capital em instalações de máquinas, em edifícios, etc.". Com isso, extrair-se-ia ao máximo a habilidade de produzir do operário, de forma que tempo algum do processo de produção fosse inutilizado. Era preciso aumentar a capacidade produtiva do trabalho e baixar o preço de custo, o que geraria uma produtividade mais lucrativa para os capitalistas. Era preciso aperfeiçoar os métodos de racionalização da produção para se executar em ritmo mais rápido e com maior eficiência os tipos mais elevados de trabalho.

A aplicação dos métodos científicos ao processo de trabalho visava a economia de tempo e o acréscimo de rendimento do trabalho obtido "pela eliminação de movimentos desnecessários e [pela] substituição de movimentos lentos e ineficientes por movimentos rápidos em todos os ofícios" (TAYLOR, 2008, p. 33). No contexto histórico em que o referido teórico propõe o controle dos tempos e dos movimentos já havia nas fábricas uma divisão (hierárquica) do trabalho baseada na separação entre os que administravam e os que produziam.

Porém, ele acreditava que mesmo já dividido o sistema de produção podia ser ainda mais fragmentado, já que o acúmulo de tarefas dentro de cada uma dessas funções impossibilitava o seu cumprimento com a rapidez e precisão necessárias.

Para o estadunidense, não era recomendado confiar na "iniciativa" dos trabalhadores. Há, no seu entendimento, uma tendência de os trabalhadores fazerem "cera", isto é, utilizar métodos que diminuem suas possibilidades de produção, o que acarreta, sempre, prejuízo para os capitalistas.

Intentando atacar as estratégias dos trabalhadores contra a disciplina de trabalho imposta, Taylor (2008, p. 27) constata que a eliminação do hábito de fazer "cera" "adviria, em média, aumento de cerca do dobro da produção de cada homem e de cada máquina". Buscou-se, então, remover a "cera" e o "trabalho retardado", fazendo com que os trabalhadores operassem suas atividades do melhor modo e mais rapidamente possível para que decresça o custo da produção e amplie significativamente a produção da mais-valia. Como suporte, eles receberam a "cooperação" da gerência científica no que diz respeito ao disciplinamento. 
As estratégias produtivas passariam a ser aplicadas pela gerência, aprimorando aquelas que possibilitam a realização do trabalho em conformidade com as "leis científicas" que demarcam a melhor divisão de responsabilidades: dadas as condições estruturais de hierarquia estabelecidas na fábrica, a direção e os setores de chefia cuidam do planejamento e da organização produtiva; o trabalhador, privado das suas funções de controle, apenas operacionaliza o que a administração orquestra. Fica notório que o taylorismo põe a necessidade de um tipo de homem para planejar e outro tipo, diferente, para executar o trabalho.

O trabalho passa a ser comandado pela gerência que cristaliza as tarefas de organizar, planejar, supervisionar e controlar a produção de forma a favorecer a obtenção de lucros por parte do capital. Consequentemente, o capitalista aprende a tirar vantagens desse aspecto da força de trabalho humana e a quebrar a unidade do processo de trabalho, este agora sendo realizado em distintos lugares e por trabalhadores distintos. Estudiosos como Braverman (1981) e Filho e Gurgel (2016) muito bem constatam que o trabalhador, no processo de trabalho, não combina mais as atividades entre mão e cérebro ao passo em que se reduzem os trabalhadores ocupados diretamente com a produção, despojam-se as funções mentais que consomem tempo e se atribui a outrem tais funções.

Para garantir o controle absoluto da empresa sobre os trabalhadores, a gerência precisaria subordinar o trabalhador às formas rigorosas em que 0 trabalho deveria ser executado. Os trabalhadores acabam por perder o controle sobre os instrumentos de produção, o trabalho e o modo e ritmo da execução. É tão assim que "este controle pertence agora aqueles que podem 'arcar' com o estudo dele a fim de conhecê-lo melhor do que os próprios trabalhadores conhecem sua atividade viva" (BRAVERMAN, 1981, p.106). Com efeito,

Tanto a fim de assegurar o controle pela gerência como baratear o trabalhador, concepção e execução devem tornar-se esferas separadas do trabalho, e para esse fim o estudo dos processos do trabalho devem reservar-se a gerência e obstado aos trabalhadores, a quem seus resultados são comunicados apenas sob a forma de funções simplificadas, orientadas por instruções simplificadas o que e seu dever seguir sem pensar e sem compreender os raciocínios técnicos ou dados subjacentes (BRAVERMAN, 1981, p.107). 
O fordismo, por sua vez, foi desenvolvido por Henry Ford que desde sua juventude demonstrava interesse pela mecânica e por motores automotivos. Ford construiu sua primeira fábrica de carros em 1896 e, após anos de pesquisas, recebeu reconhecimento público por seu trabalho; construiu a planta do que se tonaria a maior fabricante mundial de veículos automotores: a Ford Motor Company. Havia no pensamento de Ford uma diferença significativa (entretanto, complementar) em relação a Taylor: "era a sua visão, seu reconhecimento explícito de que produção de massa significava consumo de massa" (HARVEY, 2010, p. 122), pois apenas esse tipo de produção diminuiria os custos operacionais da produção e o preço em que o carro seria comercializado.

Ford busca estabelecer um novo sistema de reprodução da força de trabalho consoante à política de gerência e controle do trabalho tayloriana. Ao aplicar este novo sistema, introduzindo oito horas de trabalho e um ordenado de U\$ 5 como recompensa aos trabalhadores, Ford manteve disciplinados os trabalhadores e também possibilitou a eles "renda e tempo de lazer suficientes para que consumissem os produtos produzidos [...] que as corporações estavam por fabricar em quantidades cada vez maiores" (HARVEY, 2010, p. 122).

$\mathrm{O}$ fordismo consiste numa organização produtiva rígida, interiorizada ${ }^{5} \mathrm{e}$ uniformizada que suscitou a racionalização das operações, eliminando o desperdício de tempo no espaço fabril e aumentando o ritmo a exploração do trabalho. Uma de suas principais características é o parcelamento das tarefas. Ao invés de produzir um veículo inteiro, um operário realiza apenas um número limitado de gestos, sempre os mesmos, durante sua jornada de trabalho. À medida que 0 fordismo fragmenta 0 trabalho em suas partes mais essenciais, decompõem-se, em seu grau máximo, as tarefas realizadas por cada trabalhador de forma parcelada. Limita sua atividade a movimentos repetitivos cuja somatória resultava na produção do veículo completo. Através do parcelamento, o trabalhador não precisaria mais ser um artesão especializado em mecânica.

Em sintonia com o referido parcelamento que resulta na desqualificação do operário, tem-se a criação estratégica da linha de montagem cuja função é interligar os diversos trabalhos realizados separadamente. Na fábrica,

\footnotetext{
${ }^{5} \mathrm{~A}$ produção fordista desenvolve-se internamente na fábrica, "recorrendo-se apenas de maneira secundária ao fornecimento externo, ao setor de autopeças" (ANTUNES, 2009, p. 39).
}

TrabalhoNecessario - www.uff.br/trabalhonecessario; Ano 15, № 27/2017 
Uma esteira rolante desfila, permitindo aos operários, colocados um ao lado do outro, realizar as operações que lhes cabem. Além de ligar os trabalhos individuais sucessivos, a linha fixa uma cadência regular de trabalho, controlável pela direção da empresa. Permite uma produção fluida, limitando ao máximo os estoques entre operações (GOUNET, 1999, p. 19).

Ao alinhar seu pensamento ao de Taylor, Ford desenvolve a linha de produção em série que, na sinótica formulação de Pinto (2010, p. 35 e 36), pode ser assim descrita:

A colocação do objeto de trabalho num mecanismo automático que percorresse todas as fases produtivas, sucessivamente, desde a primeira transformação da matéria-prima bruta até 0 estágio final (como o acabamento do produto, por exemplo). Ao longo dessa linha, as diversas atividades de trabalho aplicadas à transformação das matérias-primas ou insumos foram distribuídas entre vários operários fixos em seus postos, após terem sido suas intervenções subdivididas em tarefas cujo grau de complexidade foi elevado ao extremo da simplicidade.

Na fábrica fordista, "no lugar dos homens responsáveis pelo deslocamento dos materiais e objetos de trabalho, máquinas automáticas passaram a se encarregar por tal, suprindo [parcialmente] o trabalho humano" (PINTO, 2010, p. 37). Com a linha de montagem, os objetos se deslocavam ao longo da esteira rolante sem a ajuda direta do trabalhador. Ao homem restava apenas seguir 0 ritmo de trabalho das máquinas, num processo contínuo de repetição de movimentos. Observa-se, deste modo, que o objetivo da linha de montagem é tornar o ato de produzir simplificado, onde qualquer pessoa possa executar as operações sem que precise ter a menor experiência, tornando-se, assim, a força humana uma extensão da maquinaria que baliza a cadência da produção.

O sistema Ford ainda se comporia pela produção em massa dos produtos, o que requereu muitos consumidores para comprar as mercadorias. Para a rigidez da produção era também imprescindível a padronização das peças, produzindo grandes quantidades de produtos com pouquíssimos graus de diferenciação, duradouros - porque "desejaríamos produzir artigos de duração ilimitada e jamais fazermos mudanças inúteis que ponham fora de moda os nossos carros

TrabalhoNecessario - www.uff.br/trabalhonecessario; Ano 15, №27/2017 
vendidos" (FORD, 1964, p. 110) - e a preços baixos, uma vez que "toda vez que, sem prejuízo da qualidade, se diminui o preço de um carro, cresce o número de compradores" (FORD, 1964, p. 119). Esse processo dotava o capital de maior intensidade na extração do sobretrabalho a partir de uma produção homogeneizada e enormemente verticalizada, controlada de cima a baixo. Permitia a intensificação do trabalho humano desenvolvido em limites cada vez mais estreitos de tempo e possibilitava elevadíssimas taxas de lucratividade ao sistema do capital naquele contexto particular da monopolização capitalista.

De modo a garantir a produção em larga escala e minar o poder de resistência dos trabalhadores que se contrapunham ao que estava sendo imposto no âmbito da fábrica, Ford propôs um aumento dos salários. Alerta Gounet (1999, p. 20, grifos nossos) que "para receber seus 5 dólares, o trabalhador deve dar provas de boa conduta, ou seja: não ser uma mulher, não beber, destinar seu dinheiro à família [...]". Evidencia-se, assim, a presença de valores conservadores que se afirmam na discriminação do trabalho feminino no contexto da produção fordista. Isso resulta, a nosso ver, da própria cultura enraizada na sociedade capitalista que supõe uma minúcia nas atividades desempenhadas pela mulher devido aos seus anseios, expectativas e certas habilidades em contraposição a uma "superioridade" nas executadas pelo homem.

Hirata, em Nova divisão sexual do trabalho?, traz alguns apontamentos sobre a presença da mulher nas fábricas sendo submetidas ao regime rígido de produção. Ao analisar as diversas expressões da exploração do trabalho feminino, através de estudos comparativos feitos em países de distintos continentes - França, Brasil e Japão -, as narrativas oferecidas pela autora aludem que as indústrias de trabalho contínuo empregam predominantemente homens no processo produtivo; já as fábricas que parcelam as tarefas, utilizavam um maior contingente de mulheres do que de homens em seu quadro funcional. Em suas palavras: "o trabalho sob forte pressão do tempo, ligado a uma organização do trabalho baseada em princípios tayloristas, é efetuado, sobretudo, por jovens operárias" (HIRATA, 2002, p. 30).

O trabalho executado pelas mulheres nas fábricas fordistas seguia uma padronização, fragmentação e estava a todo instante controlado 
cronologicamente de modo a evitar o desperdício na produção, o que nem sempre acontecia com o trabalho dos homens. Em cada país por ela pesquisado, a produção e o trabalho exercido pelas mulheres ocorriam de forma peculiar, correspondendo à realidade nacional; porém, não obstante as diferenças e variações geocontinentais identificáveis, sobre as condições de trabalho a que as mulheres eram submetidas de forma geral, Hirata (2002, p. 30) revela que "robôs industriais ou cadeia de montagem clássica com tecnologias diferentes podem corresponder a condições de trabalho sempre muito penosas... quando se trata de mulheres operárias".

No Japão, a título de exemplo, a proposta taylorista se valeu do aprendizado das jovens operárias que desde muito cedo são disciplinadas para a submissão familiar e laborativa. Associou-se à sua habilidade manual e à sua atenção minuciosa adquiridas na família. As fábricas japonesas estrategicamente

[...] oferecem, às suas operárias, cursos semanais de todas as artes domésticas, entre as quais a arte do arranjo de flores (ikebana); esse trabalho analítico, minucioso, de desestruturaçãoreestruturação das flores e das folhas de acordo com uma ordem rigidamente estabelecida parece ser uma preparação para o trabalho operário, uma introdução aos gestos dissociados, às tarefas fragmentadas requeridas pela organização científica do trabalho (HIRATA, 2002, p. 31, grifo da autora).

Embora o taylorismo-fordismo se baseasse no controle coercitivo do tempo de vida e de trabalho do operário na fábrica, tal coerção se direcionava, de fato, muito mais às mulheres. As mulheres tinham seu tempo rigidamente controlado dentro do espaço fabril desde o momento de produzir até à satisfação de necessidades básicas e o descano. Basta apenas considerar, lembra Hirata (2002, p. 33), que o sistema de dormitórios de jovens operárias "tornou possível um movimento de racionalização em que o conjunto da jornada era considerado o tempo de sono, a toalete, o ato de vestir, o trabalho na fábrica", bem como "o ato de se pentear, o de defecar, o banho, as aulas e o lazer estritamente medidos".

Em relação aos homens, o padrão produtivo rígido não exercia tamanho controle. Sobre esta notável diferença, Hirata (2002, p. 31, grifos da autora) aponta suas reais razões na seguinte passagem: 
A determinação exata da quantidade de tempo jamais pode ser tão coercitiva e autoritária para os homens: eles não foram educados desde a infância para obedecer, aceitar e se submeter; as técnicas tayloristas, longe de serem neutras, utilizam e reforçam a divisão sexual existente tanto dentro da empresa quanto na sociedade. Os métodos tayloristas, quando extorquem o rendimento da mão-de-obra feminina, beneficiam-se do aprendizado das jovens relativo à [...] qualidades adquiridas em primeiro lugar na família, mas, em seguida, cultivadas nas próprias fábricas japonesas que oferecem, às suas operárias, cursos semanais de todas as artes domésticas.

Pode-se argumentar, e não sem razão, que a presença das mulheres no âmbito da produção rígida foi acompanhada por condições de trabalho desiguais. Remuneração inferior, controle hierárquico e intensidade de trabalho muito maiores foram reservadas às mulheres. Ora, as atividades que requeriam mais qualificação eram executadas por homens; por outro lado, e em contraste, as mulheres eram incumbidas daquelas que os empregadores acreditavam ser absolutamente compatíveis com as exercidas no espaço doméstico.

As funções de controle e gerência na produção rígida eram exercidas predominantemente pelos homens. Hirata (2002, p. 41) mostra, à luz das realidades por ela investigadas, que "as reuniões podem ser uma oportunidade de repressão direta das mulheres pela hierarquia masculina e servem, sobretudo, para controlar a qualidade de seu trabalho e a obediência aos procedimentos e às regras de produção". As mulheres não tinham autorização para participar de reuniões e nem recebiam chamados para opinar quanto às mudanças que deveriam ser feitas na empresa; sendo esses espaços, por regra, masculinizados. Em tudo isso vem à tona que a rigidez no âmbito da produção suscitou (e reafirmou em todos os níveis) uma nítida divisão sexual do trabalho: em geral, aos homens eram reservadas principalmente as atividades de controle, com direito a alguns privilégios; e às mulheres, as atividades simples e repetitivas do processo de produção.

\section{A força de trabalho feminina no contexto do toyotismo}

Após um longo período de crescimento econômico possibilitado pela produção rígida, já por nós caracterizada, em meados de 1970 eclodem

TrabalhoNecessario - www.uff.br/trabalhonecessario; Ano 15, № 27/2017 
claramente os sinais de esgotamento do padrão taylorista-fordista, não possibilitando as condições que lograram êxito à expansão do capital. Não é à toa que desde essa década, até os dias de hoje, desencadeia-se um cenário crítico irreversível cujo movimento é característico por ser "um continuum depressivo". Uma crise "cumulativa, endêmica, mais ou menos permanente e crônica, com a perspectiva última de uma crise estrutural” (MÉSZÁROS, 2002, p. 697).

Atingindo todos os ramos da produção e não se restringindo apenas a algumas regiões geográficas específicas, a crise estrutural do capital acomete todos os países capitalistas, sejam periféricos ou centrais, desenvolvidos ou em desenvolvimento. Em sua extensão de espaço e tempo, impacta significativamente o sistema social vigente e todas as dimensões da vida humana (economia, política, arte, ciência, valores, educação, relações pessoais e familiares). E porque isso? Porque, advoga o autor,

\begin{abstract}
Em termos simples e gerais, uma crise estrutural afeta a totalidade de um complexo social em todas as relações com suas partes constituintes ou subcomplexos, como também a outros complexos aos quais é articulada. Diferentemente, uma crise não estrutural afeta apenas algumas partes do complexo em questão, e assim, não importa o grau de severidade em relação às partes afetadas, não pode pôr em risco a sobrevivência contínua da estrutura global (MÉSZÁROS, 2002, p. 796-797, grifo do autor).
\end{abstract}

Muito embora se tenha a instalação de uma crise destas proporções isso não impede que o capital continue exercendo dominação sobre o conjunto da humanidade. Visando à maximização dos lucros, o capital se vê compelido a encontrar alternativas para o quadro crítico e longevo em que é absorvido no sentido de reordenar tanto a produção e as formas de acumulação quanto o controle da sociedade. Presencia-se uma ofensiva que atinge a dinâmica do trabalho e a reprodução dos trabalhadores em todos os níveis. Não por acaso, mas em decorrência desse processo, é notável o insuficiente atendimento das necessidades sociais de maior parte da população, os elevados índices de pauperização, a precarização das relações de trabalho, a intensificação da exploração e o agravamento do desemprego.

Por não mais suprir as necessidades do capital, o padrão rígido precisou ser substituído ${ }^{6}$ por um novo padrão centrado na flexibilidade que responde no

\footnotetext{
${ }^{6}$ Uma ressalva importante para se evitar conclusões errôneas: a emersão dum novo padrão não rompe, por completo, com os preceitos do padrão anterior. Por isso, "[...] o fordismo não foi superado para que as técnicas do modelo de gestão japonês sejam introduzidas; as duas formas convivem, em determinadas experiências, de forma complementar e, até mesmo, desigual. Há nesse sentido, contradições reveladoras de que a absorção de um novo modo de organização do

TrabalhoNecessario - www.uff.br/trabalhonecessario; Ano 15, № 27/2017
} 
âmbito econômico às novas exigências. Deflagrou-se, no enfrentamento ao contexto recessivo, um conjunto de transformações na produção por meio da constituição do avanço tecnológico - microeletrônica, informática e automação -, das formas de acumulação flexíveis advindas do toyotismo, das formas de gestão organizacional, do downsizing e do desmonte de direitos trabalhistas outrora conquistados por meio de muitas lutas históricas e seculares.

Consolidado no Japão, nos anos pós-guerra, o toyotismo foi idealizado por Toyoda Sakichi, Toyoda Kiichirõ e Taiichi Ohno para responder às necessidades econômicas daquele país. Em seguida, ocidentalizou-se e se espraiou da Itália aos Estados Unidos, do Japão ao Brasil, tornando-se o modelo de produção predominante nas companhias que enfrentavam o desafio da diversificação.

Se é certo que este novo padrão também busca obter produtividade e lucro, não deixa de ser verídico o fato de que ele se distingue do que the antecedeu. O padrão de produção em massa era, como demonstramos, totalmente contrário a mudanças dada a sua rigidez. Já o toyotismo, funcionando generalizadamente numa etapa histórica de crise da economia mundial, adaptase bem às condições de diversificação impostas pela dinâmica produtiva. De milhões de mercadorias idênticas, experimenta-se a rota inversa: uma produção que atende a demandas individualizadas, evitando a queda da taxa de lucro tão temida pelos capitalistas. Em sua totalidade, a produção é sempre diversificada variações de modelos, tamanhos, estilos e serviços - e conduzida diretamente pela demanda, realizando-se em pequena escala e com estoque mínimo.

No toyotismo, tem-se a eliminação absoluta dos desperdícios provenientes da superprodução desmedida e da produção de produtos defeituosos; o melhor aproveitamento do tempo através do princípio do just in time (apenas-a-tempo) que nada mais é senão a possibilidade de "adquirir os produtos na hora e na quantidade necessárias" (OHNO, 1987, p. 131); a instalação do sistema de kanban - placa de comando que avisa quando é necessário repor peças; a flexibilização do trabalho e a polivalência do trabalhador. Sob o signo da flexibilização, a produção requer que o trabalhador antes responsável apenas por uma atividade deixe de ser monofuncional e passe a operar com celeridade 0 2011, p. 92).

TrabalhoNecessario - www.uff.br/trabalhonecessario; Ano 15, №27/2017 
máximo de funções possíveis. Consolida-se a empresa enxuta (lean production) que mesmo dispondo de um menor contingente de trabalhadores alcança maiores índices de produtividade mediante os métodos de superexploração.

Com as mudanças introduzidas pelo toyotismo, presencia-se uma maior intensificação da exploração do trabalho porquanto o trabalhador desempenha várias funções ao mesmo tempo, senão será demitido de seu posto de trabalho. O trabalhador, defrontando-se com condições aviltantes de trabalho, subsiste apenas para produzir aquilo que o sistema Ihe impõe. Proliferam-se, ademais, trabalhos precários, terceirizados, informais (comumente identificados como "autônomos") e temporários que afetam a vida dos sujeitos neles envolvidos.

Ainda que as novas formas de acumulação de capital afetem toda a classe trabalhadora, as mulheres são, em determinados ramos, as mais atingidas. Os efeitos perversos, desiguais e excludentes do processo de reestruturação produtiva, com a flexibilidade do trabalho, repercutem de forma particular sobre as mulheres. Homens e mulheres estão inseridos de modo distinto no universo produtivo e, sendo assim, vivenciam as mudanças com disparidades.

O toyotismo na França e no Japão, para darmos enfoque específico a duas realidades de outras possíveis, é baseado numa divisão sexual e "setorial":

Na França, há uma nítida divisão do trabalho entre o setor de preparação (processo), com mão-de-obra exclusivamente masculina, e o setor de embalagem, em que a população é mista. No Japão, algumas operárias polivalentes tinham acesso às salas de controle do setor de preparação e nele podiam trabalhar, mas essa mobilidade entre setores estava longe de ser generalizada. As operárias estavam maciçamente confinadas nas salas de embalagem, onde todos os chefes de equipe e os operários da manutenção eram homens (HIRATA, 2002, p. 95).

Nesses países, as mulheres são, desde cedo,

Recrutadas somente para as chamadas profissões femininas (não-qualificadas e com baixos salários) do setor secundário e [...] de serviços, a seleção é feita conforme a atitude, as maneiras, o comportamento: observação das regras de etiqueta, proibição de calças compridas, proibição de fumar durante 0 trabalho, submissão e obediência (HIRATA, 2002, p. 136, grifo da autora). 
Diante do trabalho em tempo parcial, dos empregos precários e da posição desfavorecida, assiste-se à bipolarização dos empregos femininos que tem acirrado as desigualdades sociais entre os homens e as mulheres e entre as próprias mulheres. De um lado, tem-se "um polo constituído por mulheres executivas de profissões intelectuais superiores, categorias que se feminizam (médicas, advogadas, juízas, arquitetas, jornalistas, professoras universitárias, pesquisadoras, assalariadas do ramo da publicidade e da arte, etc.)". Do outro, estão "mulheres que se mantêm nas ocupações tradicionalmente femininas: funcionárias públicas, da saúde, da educação, dos serviços aos particulares, auxiliares de enfermagem, enfermeiras, professoras primárias" e "profissionais do home care - que atendem pessoas idosas, doentes, crianças, e que fazem o trabalho doméstico como empregadas, faxineiras, etc." (HIRATA, 2009, p. 30).

$O$ aumento quantitativo de mulheres nos postos de trabalho não foi - e essa é uma das contradições do processo de flexibilização da produção acompanhado pela melhoria qualitativa das condições sob as quais se labuta. Ao invés disso, o que se tem é, seja na Ásia, na Europa ou na América Latina, precarização e vulnerabilidade crescentes. Os empregos são instáveis, precários, mal remunerados e pouco valorizados socialmente. Outrossim, no padrão produtivo em voga persistem indícios de segregação vertical nas fábricas e empresas expressos na conhecida dificuldade de ascensão profissional a postos de direção e/ou à chefia que são, por vezes, nulas para as mulheres, sem falar da limitação ou inexistência de direitos atinentes.

No que se refere ao trabalho precário que atinge majoritariamente 0 trabalho feminino, esse fenômeno é agravado devido às migrações internacionais de mulheres que, sem pertences e sem pertencimento, quando empregadas tornam-se faxineiras, domésticas, babás, assistentes maternais, dentre outras profissionais. Na França, elucida a autora,

[...] as imigrantes são ligeiramente mais numerosas do que os homens, ao passo que estes eram majoritários até 1999 [...]. Essas mulheres encontram-se com frequência em situação precária, pois raramente têm contratos que garantam todos os direitos sociais. Esta precariedade pode ser associada à hipótese da "corveabilidade" [...], que articula relação social de sexo à relação de classe e à relação de serviço e atualiza a ideia de uma relação de servidão estreitamente integrada à relação de serviço 
em certas circunstâncias e para certas categorias de mão-de-obra (HIRATA, 2009, p. 31).

Nos território japonês, Hirata e Zarifian (1991, p. 179) diagnosticaram que o trabalho profissional das mulheres é estruturado de uma forma radicalmente diferente do dos homens. E se se considerar a partir da faixa etária dos 20 aos 25 anos, a taxa de atividade das mulheres cai brutalmente. Chega a declinar a um nível aproximado de $45 \%$ e se eleva novamente a cerca de $65 \%$ para a faixa de idade dos 40 aos 55 anos.

Como consequência dessa realidade,

[...] as mulheres jovens que, teoricamente, poderiam ter acesso ao sistema de emprego vitalício, estando empregadas como assalariadas estáveis em grandes empresas, são, de fato, precocemente rejeitadas quando estão em idade de ter filhos e forçadas, social e materialmente, a dedicar-se exclusivamente à atividade doméstica. Uma vez terminada a criação dos filhos, para uma parte dentre elas, o retorno a uma atividade assalariada as exclui do sistema dominante de emprego e torna-as, de fato, uma das reservas privilegiadas da constituição de mão-de-obra precária, especialmente as assalariadas em regime parcial (HIRATA e ZARIFIAN, 1991, p. 180).

A lógica flexibilizadora impulsiona uma gigante terceirização do trabalho. Partes do processo para execução de um produto podem ser realizadas em ambientes externos às fábricas, reeditando, desde o final dos nos 1980, o trabalho domiciliar". Neste, "as mudanças se traduzem em jornadas de trabalho mais longas, que se estendem, às vezes, pela noite e aos finais de semana e feriados; em locais de trabalho improvisados"; também "na ausência de proteção social|8; na diminuição do poder de reivindicação e de negociação; [e] na superexploração do trabalho da mulher" (TAVARES, 2004, p. 171).

$O$ trabalho feminino pode ser notado também no Sistema de Vendas

Diretas (SVD) que é travestido como sendo uma atividade que possibilita "autonomia" para quem a desenvolve. Devido a sua dinâmica, a adesão ao SVD acontece associada à flexibilização do trabalho. Por não ter formas definidas de

\footnotetext{
${ }^{7}$ O relatório da OIT (2016) retrata que, só no ano de 2015, 586 milhões de mulheres no mundo estavam trabalhando por conta própria ou trabalhando para uma unidade domiciliar.

${ }^{8} \mathrm{O}$ levantamento realizado pela OIT revela que "quase 40 por cento das mulheres no trabalho remunerado não contribuem para nenhum sistema de proteção social. Esta proporção atinge 63,2 por cento de mulheres na África subsaariana e 74,2 por cento na Ásia Meridional, onde o emprego informal é a forma dominante de emprego. Na Ásia Meridional, por exemplo, o emprego informal representa mais de 80 por cento do emprego não-agrícola. O emprego informal é, em três de seis regiões, a maior fonte de emprego não-agrícola para mulheres, mais do que para os homens (África subsaariana, América Latina e Caraíbas e Ásia Meridional). Neste contexto, o diferencial entre homens e mulheres no emprego informal pode atingir os 13 pontos percentuais, como é o caso da África subsaariana" (OIT, 2016, p. 5).
}

TrabalhoNecessario - www.uff.br/trabalhonecessario; Ano 15, № 27/2017 
trabalho, ele se adéqua à potencialidade da informalidade e às atividades precárias e de baixa remuneração. Tal sistema tem aglutinado milhares de

[...] mulheres que arcam com riscos de estocagem e inadimplência, podem assumir a jornada dupla-concomitante de um trabalho que se realiza imbricado em outras atividades, ao mesmo tempo que são consumidoras assíduas dos produtos. Fica claro também que só terão alguma remuneração significativa mulheres que tornem esta sua ocupação principal ou a conciliem intensamente com outras ocupações. Para as que transitam mais nebulosamente entre o ser vendedora e o vender para consumir, o que fica para a análise é uma dúvida, senão uma hipótese, de que no fim das contas estejam pagando para trabalhar (ABÍLIO, 2014, p. 83-84).

O SVD "pode, então, assumir diferentes faces: a do complemento da renda familiar; a de uma ocupação alternativa ante a rotatividade do mercado de trabalho e a de um trabalho que não ponha em jogo o papel familiar feminino tradicionalmente estabelecido" (ABÍLIO, 2014, p. 90). Por seu intermédio, a mulher passa a experienciar atividades que não Ihes propicia qualquer tipo de garantia trabalhista, mas tão-só o complemento dos rendimentos caseiros. Temse a inserção "oportuna" de mulheres que são precocemente expulsas do mercado formal de trabalho. E, no quadro mencionado, o SVD serve para ludibriar as trabalhadoras ao difundir a ideologia de que a mulher trabalha "sem trabalhar".

Ao analisar "o make up do trabalho" no Brasil, a autora indaga-se sobre onde está o controle das revendedoras e chega à conclusão de que a produção nas fábricas de cosméticos que funcionam sob a lógica do SVD acontece

[...] pautada por um trabalho sem formas nem regulações definidas, e de dimensões gigantescas. Mas a ausência de formas não significa ausência de controle; significa que o controle se adapta à informalidade e opera de modos menos reconhecíveis. As promotoras de vendas têm um papel fundamental: trabalhando com metas e bonificações, o desempenho delas, assim como a remuneração, está plenamente vinculado à produtividade. Elas coordenam seus setores, instruem sobre os novos produtos, dão "dicas" de vendas, sorteiam produtos e criam suas próprias estratégias de motivação das vendedoras nas reuniões (ABÍLIO, 2014, p. 145).

Paralela a essas realidades, que nos parecem de extrema pertinência para delinear algumas expressões do objeto aqui em estudo, outra nos é oferecida por 
Holzmann (2000). Os estudos da autora voltados para o entendimento da estrutura ocupacional por sexo indicam que os comportamentos culturalmente entendidos como sendo típicos da mulher - a saber: paciência, perspicácia, fidelidade, maior aceitação de trabalhos tediosos e resistência à monotonia, que "resultam em maior docilidade à dominação do capital" - garantem uma superexploração da força de trabalho feminina traduzida na concentração das mulheres em níveis inferiores quanto à qualificação, à valorização das tarefas e à remuneração, e uma subordinação à autoridade masculina no trabalho.

Enquanto os homens se distribuem em todos os ramos da atividade industrial e nas ocupações do setor de serviços, as mulheres, vítimas duma hierarquia horizontalmente imposta, se concentram em algumas poucas categorias ocupacionais, em determinadas especialidades.

Nas sociedades industrializadas, a mão-de-obra feminina se concentra nas indústrias de alimentos, têxteis, de confecção e de calçados e, mais recentemente, na eletrônica. No setor terciário, as mulheres estão ocupadas, predominantemente, no comércio, nos escritórios e nos serviços profissionais de educação, saúde e bem-estar. Estudos de categorias profissionais ou que tomam como objeto um determinado local de trabalho (fábrica, banco, estabelecimento comercial) revelam uma outra forma de segregação, vertical [...], que atua sobre a mão-de-obra feminina, pela qual ela se concentra nos níveis mais baixos da hierarquia técnica, funcional e salarial na estrutura das empresas ou nas categorias ocupacionais (HOLZMANN, 2000, p. 261).

E complementa a autora:

[...] em especial na indústria, as tarefas reservadas às mulheres são, via de regra, as consideradas mais leves, mais simples e inegavelmente, as mais repetitivas e mais monótonas, que requerem mais paciência e execução mais minuciosa, porque, explícita ou tacitamente, elas são entendidas como mais adequadas às aptidões consideradas inerentes à mão-de-obra feminina. Sistematicamente, essas tarefas são também consideradas não qualificadas (HOLZMANN, 2000, p. 261 - 262).

No campo de prestação de serviços, uma área que se destaca no emprego da força de trabalho feminina é o setor da Tecnologia da Informação (TI) que, na década de 80 do século passado, apresentou-se enquanto uma possibilidade de criar condições de maior igualdade para homens e mulheres no mercado de

TrabalhoNecessario - www.uff.br/trabalhonecessario; Ano 15, № 27/2017 
trabalho bem como "melhores" oportunidades de remuneração e promoção para aquelas. No universo da $\mathrm{TI}$, as mulheres se inserem em diversos espaços, entre eles registra-se com grande visibilidade o setor de teleatendimento, conhecido também como telemarketing ou, ainda, call center.

As atividades desenvolvidas pelas trabalhadoras nas empresas de call center podem ser assim caracterizadas:

É um desdobramento das atividades de telefonista. Em geral, essa atividade consiste em fornecer informações aos usuários, sendo utilizada constantemente uma única ferramenta, a voz, através do computador e do fone de ouvido. A rotina das teleoperadoras é exaustiva e pesada. As ações são repetitivas e submetidas a um rigoroso controle por parte da empresa, o que pode gerar, muitas vezes, problemas de ordem física e psicológica (NOGUEIRA, 2008, p. 75).

O trabalho realizado pelas teleoperadoras nas empresas podem trazer sérios riscos à vida das mulheres, pois, além da superexploração na realização de atividades repetitivas, na maioria das vezes o call center possui uma dinâmica de produção baseada no domínio do tempo, o que consequentemente faz com que as trabalhadoras tenham poucas pausas e horas de descanso. Os fatores de risco mais comuns diante das jornadas rotineiras são: ritmo alucinante de trabalho; ausência de pausas para recuperar o organismo; metas de produtividade desgastantes (tempo médio de atendimento - TMA); movimentos recorrentes; pressão constante de supervisores com controle rígido do trabalho; insalubridade; inadequação do mobiliário e dos equipamentos; e postura estática.

Atreladas a isso, desenvolvem-se várias lesões musculares que vão alterando evolutivamente os tendões, as articulações e os músculos, manifestando-se, de início, como dor e podendo chegar, em casos avançados, à incapacidade funcional. Desenvolvem-se, ainda, doenças auditivas provocadas pelo ruído do fone de ouvido e aquelas relacionadas à voz, instrumento fundamental da teleoperadora, diagnosticadas como nódulos vocais. No que toca à saúde mental, é comum a incidência do estress, da neurastenia, da fadiga, da neurose profissional e duma série de transtornos que acometem o bem-estar. 
Tomando como lócus de estudo a agroindústria brasileira, Nogueira (2011) revela como ocorre a organização familiar e a divisão sexual do trabalho no espaço rural. Em um exame caucionado na tradição marxista, sustenta a autora:

$\mathrm{Na}$ família dos pequenos produtores rurais, esta divisão "é permeada também pela tradicional e cultural dominação masculina", só que de forma mais intensa que na maioria das famílias urbanas, resultando em "uma desigualdade" mais acentuada, "tanto nas relações de trabalho quanto nas relações" familiares. A divisão sexual do trabalho nas pequenas propriedades familiares rurais apoia-se, em grande medida, na dominação presente na hierarquia familiar, como por exemplo, as relações de herança e propriedade, os arranjos matrimoniais, etc. (NOGUEIRA, 2011, p. 191).

No seio da organização familiar observa-se uma divisão sexual do trabalho baseada na hierarquização onde 0 homem tem 0 papel preponderante de responsabilidade pela manutenção do lar: comanda e define o tipo de atividades a serem desempenhadas na propriedade, 0 trabalho a ser realizado pelos membros, o comando financeiro dos recursos, a decisão de novos investimentos. A despeito do trabalho das mulheres, este fica restrito quase que exclusivamente ao espaço reprodutivo: cuidar da casa, cozinhar, educar os filhos, cultivar as hortas e os jardins, lidar com pequenas criações de gado, aves e suínos.

Mesmo com as lutas encabeçadas pelas mulheres, as atividades laborativas que estas exercem no meio rural tiveram poucas modificações ao longo do tempo; e isto se deve, em grande parte, à cultura patriarcal que atinge as mulheres nos espaços urbanos, como também remeta-se ao segmento rural.

Essas são, em resumo, algumas expressões do trabalho feminino no contexto da flexibilidade do trabalho decorrente do movimento de reestruturação do capital instaurado em resposta à crise por ele experimentada.

\section{Considerações finais}

Diante do que foi exposto, e com base nas referências estudadas, pôde-se identificar que as desigualdades provenientes da divisão sexual do trabalho afetam um contingente significativo de mulheres em várias regiões do mundo. Apresentaram-se, no trato histórico dessa questão, as condições objetivas sob as 
quais ocorre o controle e a exploração da força de trabalho feminina durante a produção rígida e, em seguida, no contexto da flexibilidade toyotista.

Ao resgatarmos as características do padrão produtivo taylorista-fordista, verificamos que a exploração da força de trabalho feminina ocorreu mediante a submissão da mulher a um regime rígido de produção. Verificamos também que suas atividades eram realizadas sob forte pressão de tempo, resultando num trabalho rotineiro, padronizado e fragmentado. Nesse padrão, os homens usufruíam de privilégios que eram negados às mulheres. Estas, além de serem duramente controladas, eram proibidas de opinar em assuntos referentes à produção e participar das reuniões que ocorriam dentro da fábrica fordista.

Particularmente em relação ao trabalho feminino no contexto do toyotismo padrão baseado na flexibilização da produção e na exigência de um trabalhador capaz de exercer várias funções ao mesmo tempo -, deu-se ênfase à constatação de que ocorre a intensificação do ritmo de trabalho e a precarização das condições em que se executam as tarefas. Muito embora as mudanças advindas com a produção flexível tenham incidências sobre a vida da classe trabalhadora em sua totalidade, argumentamos (e, mais: demonstramos) que as mulheres são, em muitos casos, as mais atingidas. Diante da flexibilização do trabalho, os homens se distribuem em todos os ramos da atividade industrial e no setor de serviços; as mulheres, em particular, se concentram nas empresas ou, na maioria das vezes, em categorias ocupacionais terceirizadas e informais, onde são destinadas atividades precárias, monótonas e mal remuneradas que devem ser associadas àquelas desenvolvidas no espaço doméstico, o que tem configurado as expressões contemporâneas da exploração do trabalho feminino.

Uma das tendências observadas a partir do toyotismo é a expansão do emprego de mulheres em variadas áreas. Entende-se que, embora isso possa representar, em alguma medida, avanços para as mulheres e tenha trazido mudanças para suas vidas, tal expansão, ao estar trelada às exigências do capital, apresenta, como face do mesmo processo, contradições. O que se pode notar é que ela se dá principalmente nos espaços aqui ilustrados. E mais: as atividades domésticas continuam prioritariamente sendo exercidas por mulheres que acabam assumindo uma jornada de trabalho intensiva, extensiva e 
intermitente, como sugere as anotações feitas por Ávila (2011), redundando na forte justificação do lar como um espaço feminino.

Nessas palavras finais, duas questões importantes devem ser postas:

1) a exploração das atividades destinadas à mulher é determinada, em ritmo e grau, pela dinâmica que a produção assume numa determinada quadra histórica e, o que é mais fundamental, a maior participação da mulher no mercado de trabalho não significa que ela seja uma usurpadora do trabalho masculino, mas, assim como os homens, elas são condicionadas a vender sua força de trabalho para ter acesso a um salário. Inexistem indícios de que a presença da mulher na produção regida pelo capital se dá para usurpar o espaço antes ocupado de modo exclusivo por homens. Há, isto sim, como procuramos evidenciar, a necessidade de se incorporar a mulher nos diversos postos de trabalho para desvalorizar, subordinar e explorar sua capacidade laborativa.

2) a presença massiva da mulher no mercado de trabalho, mormente na transição do século $X X$ para o século $X X I$, não configura a sua plena emancipação; ao contrário do que é propalado, ela tem sido adequada às necessidades de expansão do capital num contexto de crise mundial que põe em xeque sua continuidade como sistema social dominante. E, quanto a isso, queremos fechar estas reflexões afirmando que só se pode vislumbrar a emancipação feminina consoante à emancipação do trabalho. Não há como a mulher ser emancipada do controle, da exploração e das hierarquias que a produção capitalista impõe para os trabalhadores, mesmo que haja, diante das (importantes e legítimas) lutas feministas seculares, o reconhecimento e o atendimento de algumas das suas reivindicações trabalhistas.

De tudo isso se apreende que a superação das problemáticas que envolvem a classe trabalhadora, incluindo-se aí a exploração da força de trabalho feminina enquanto expressão concreta das contradições e antagonismos presentes na ordem social vigente, só será possível com a instauração de outra forma de sociabilidade livre e radicalmente emancipada do domínio do capital. Caso se queira avançar nesse intento, torna-se imprescindível a luta contínua e cotidiana contra as amarras que aprisionam nos últimos séculos o trabalho aos grilhões capitalistas. Essa é uma tarefa inadiável que está posta na ordem do dia. 


\section{Referências}

ABÍLIO, L. C. Sem maquiagem: o trabalho de um milhão de revendedoras de cosméticos. São Paulo: Boitempo, 2014.

ABREU, A. R. de P.; HIRATA, H.; LOMBARDI, M. R. Gênero e trabalho no Brasil e na França: perspectivas interseccionais. Trad. Carol de Paula. São Paulo: Boitempo, 2016.

ANTUNES, R. Os sentidos do trabalho: ensaio sobre a afirmação e a negação do trabalho. 2 ${ }^{\underline{a}}$ Ed. São Paulo: Boitempo, 2009.

ÁVILA, M. B. As mulheres no mundo do trabalho e a relação corpo e sujeito. Cadernos de Crítica Feminista, Recife, ano 5, n. 4, dez. 2011.

BRAVERMAN, H. Trabalho e capital monopolista: a degradação do trabalho no século XX. Rio de Janeiro: Editora Guanabara Koogan S.A., 1981.

FILHO, R. de S.; GURGEL, C. Gestão democrática e Serviço Social: princípios e propostas para a intervenção crítica. São Paulo: Cortez, 2016.

FORD, H. Caminhos da prosperidade. Rio de Janeiro: Freitas Bastos, 1964.

GOUNET, T. Fordismo e Toyotismo na civilização do automóvel. Tradução Bernardo Joffili. São Paulo: Boitempo Editorial, 1999.

HARVEY, D. Condição pós-moderna: uma pesquisa sobre as origens da mudança cultural. Trad. Adail Ubirajara Sobral e Maria Stela Gonçalves. São Paulo: Edições Loyola, 2010.

HIRATA, H. Nova divisão sexual do trabalho? Um olhar voltado para a empresa e a sociedade. São Paulo: Boitempo, 2002.

A precarização e a divisão sexual e internacional do trabalho.

Sociologias, Porto Alegre, ano 11, no 21, jan./jun., 2009.

HIRATA, H.; KERGOAT, D. Novas configurações da divisão sexual do trabalho. Cadernos de pesquisa, v. 37, nำ132, set./dez., 2007.

HIRATA, H.; ZARIFIAN, P. Força e fragilidade do modelo japonês. Estudos avançados, São Paulo, v. 5, no 12, 1991.

HOLZMANN, L. Notas sobre as condições da mão-de-obra feminina frente às inovações tecnológicas. Sociologias, Porto Alegre, ano 2, n 4, jul./dez., 2000.

KERGOAT, D. Da divisão do trabalho entre os sexos. In: HIRATA, H. (Org.) Divisão capitalista do trabalho. Tempo Social, São Paulo, v. 1, 1989.

TrabalhoNecessario - www.uff.br/trabalhonecessario; Ano 15, №27/2017 
MÉSZÁROS, I. Para Além do Capital. Tradução P. C. Castanheira e S. Lessa. São Paulo: Boitempo, 2002.

NOGUEIRA, C. M. O duplo trabalho feminino: o exemplo das teleoperadoras. Confluências - Revista Interdisciplinar de Sociologia e Direito, v. 10, n 2, 2008.

ano IV, $n^{\circ}$ 6, 2010. . As relações de gênero no trabalho e na reprodução. Aurora, . Integrar desintegrando: as metamorfoses no mundo do trabalho feminino, na agroindústria. Lutas sociais, São Paulo, № 27, 2011.

OHNO, T. O sistema Toyota de produção: além da produção em larga escala. Trad. Cristina Shumacher. Porto Alegre: Bookman, 1987.

OIT. Mais mulheres optam por trabalhar, mas igualdade de gênero no trabalho ainda está longe. Disponível em: <www.oitbrasil.org.br/content/mais-mulheresoptam-por-trabalhar-mas-igualdade-de-g\%C3\%AAnero-no-trabalho-aindaest\%C3\%A1-longe>. Acesso em 20 de outubro de 2016.

Mulheres no trabalho: tendências 2016. Disponível em: <http://www.ilo.org/wcmsp5/groups/public/dgreports/dcomm/publ/documents/publi cation/wcms_457096.pdf>. Acesso em 28 de dezembro de 2016.

PINTO, G. A. A organização do trabalho no século 20: taylorismo, fordismo e toyotismo. 2a Ed. São Paulo: Expressão Popular, 2010.

SAFFIOTI, H. I. B. A mulher na sociedade de classes: mito e realidade. Petrópolis: Vozes, 1976.

. O poder do macho. São Paulo: Moderna, 1987.

SOUZA, R. M. Controle capitalista e reestruturação produtiva: o Programa Brasileiro da Qualidade e Produtividade. Maceió: EDUFAL, 2011.

TAVARES, M. A. Os fios (in)visíveis da produção capitalista: informalidade e precarização do trabalho. São Pulo: Cortez, 2004.

TAYLOR, F. W. Princípios de Administração Científica. Trad. Arlindo Vieira Ramos - 8를. São Paulo: Atlas, 2008.

Recebido em: 12 de janeiro de 2017

Aprovado em: 26 de outubro de 2017

Publicado em: 5 de dezembro de 2017 